\title{
UTOPÍA Y DESENGAÑO: ANÁLISIS COMPARATISTA DE LOS LIBROS DE VIAJES A LA URSS
}

\author{
JAVIER SÁNCHEZ ZAPATERO \\ Universidad de Salamanca
}

\begin{abstract}
Resumen
El impacto de la Revolución Rusa sobre la sociedad occidental motivó la adhesión incondicional de un amplio sector de intelectuales. Muchos de ellos se desplazaron a la URSS para presenciar los cambios efectuados en la sociedad soviética, dejando testimonio de su viaje en diversas obras de carácter autobiográfico. En algunos casos, el conocimiento de la realidad soviética y de sus problemas provocó un profundo desengaño en quienes la conocieron. De ese sentimiento de desencanto nacen una serie de textos que, a medio camino entre la confesión y el libro de viajes, denuncian el estado de la sociedad soviética y se conciben como respuesta a una situación personal de crisis. Este artículo analiza las analogías existentes entre estos textos e intenta determinar su adscripción genérica.

Palabras clave: Libros de viaje, confesión, literatura comprometida, URSS, André Gide.
\end{abstract}

\begin{abstract}
The impact of the Russian Revolution on the world caused the support of an ample sector of intellectuals. Many of them moved to the USSR to be admire the changes of the Soviet society, leaving testimony of their trip in autobiographical texts. In some cases, the knowledge of the Soviet reality caused a depp disappointmet in those intellectuals. Due to this felling, writers who travelled to USSR made some texts -halfway between the confession and the travel literature- in order to denounce the situation of the Soviet society and overcome a personal situation of crisis. This article analyzes the analogies of these texts and tries to determine its genre.
\end{abstract}

Key words: Travel literature, confession, commitment, USSR, André Gide.

\section{El impacto de la Revolución Rusa en las sociedades occidentales}

L

a influencia de la Revolución Rusa sobre el mundo fue uno de los acontecimientos de mayor importancia del primer cuarto del siglo XX. Los sucesos acaecidos entre 1917 y 1921 atrajeron la atención de las sociedades occidentales, convencidas de encontrarse ante el cambio social y político más importante de la historia del mundo desde la Revolución Francesa. Así lo manifestó el literato español Pedro Garfias, quien interpretó la toma del poder por parte de los bolcheviques y las consiguientes reformas aplicadas en la sociedad rusa como "la experiencia más vasta y de interés más definitivo que ha acometido nunca la humanidad" (2001: 86). Del mismo modo, André Gide señaló en 1935, durante el Congreso Internacional de Escritores celebrado en París, que la transformación ocurrida en Rusia gracias a los sucesos 
revolucionarios liderados por Lenin ofrecía "un espectáculo sin precedentes, de una importancia inmensa [e] inesperada" (1981: 13).

Inmersa en una crisis de valores de dimensiones insondables desde finales del siglo XIX por el agotamiento de la fe en el sistema positivista y el convencimiento generalizado de que ni el desarrollo técnico, ni el progreso ni la adopción de los principios capitalistas como criterios rectores del mundo habían sido capaces de generar la felicidad y el bienestar esperados, ${ }^{1}$ la comunidad internacional concibió la revolución como la definitiva anulación del sistema de valores decimonónico. La experiencia fue interpretada de este modo como un ejemplo para buena parte de las sociedades occidentales, que, además de presenciar la primera implantación práctica de los postulados teóricos de Marx y Engels, veían en lo ocurrido en Rusia la constatación de que otro ordenamiento del mundo era posible. La URSS representaba así una alternativa al sistema capitalista, reprobado y considerado por muchos causante de las graves desigualdades y problemas existentes. De ahí que la Revolución no pueda ser analizada sólo como un mero proceso político, sino, más bien, como un acontecimiento global con ramificaciones de todo tipo. En los órdenes social, económico, moral, artístico, estético o industrial hay un antes y un después delimitados por la Revolución Rusa.

Un amplísimo número de creadores e intelectuales procedentes de todo el mundo se adhirió al ideario comunista y apoyó desde el primer momento los cambios que se estaban produciendo en el país soviético. Escritores como André Malraux -para quien los sucesos de Rusia eran "herederos de la Revolución Francesa" y una forma de "asunción del pueblo" (Todd, 2002: 200)-, Jean Paul Sartre, Pablo Neruda, George Orwell, André Gide, Arthur Koestler o Rafael Alberti mostraron su ferviente entusiasmo por la Revolución y por los cambios introducidos por el poder bolchevique. Su apoyo, materializado en manifestaciones públicas, colaboraciones con el régimen comunista e implicaciones ideológicas de sus obras literarias, se produjo en el contexto de las primeras décadas del siglo $X X$, cuando existía en un amplio sector intelectual la convicción de que el libro, y todo el arte en general, había de instrumentalizarse para la concienciación ideológica de las clases medias y populares. ${ }^{2}$ Así se explica que, además de por su carácter cosmogónico, la

1 Acontecimientos como los negativos efectos que la Revolución Industrial tuvo para el desarrollo social de las ciudades, incapaces de asumir a las grandes masas de población que se desplazaron hasta ellas en busca de un puesto en el activo mercado laboral de la época, la I Guerra Mundial, en la que por primera vez en la historia se utilizaron armas de destrucción masiva y se tomó a la población civil como objetivo o el 'crack' de Wall Street en 1929, causante de evidentes desequilibrios sociales y económicos, pusieron de manifiesto el fracaso del sistema racionalista e incidieron en la sensación de crisis experimentada por buena parte de la población de la época.

2 El protagonismo de los intelectuales en la expansión de las ideas bolcheviques fue gráficamente puesto de manifiesto por Lenin, para quien la literatura tenía que "convertirse en una literatura de partido (...) y en una parte de la causa general del proletariado" (Vázquez Montalbán, 1998: 15), y por Stalin, quien acuñó para referirse a ellos y a su función la ya clásica expresión de "ingenieros de almas". De forma similar, Máximo Gorki señaló la necesidad de que los escritores, artistas, pensadores y, en general, líderes intelectuales de la opinión pública apoyasen públicamente la Revolución: "Los intelectuales del mundo entero tienen hoy que 
revolución alcanzara su halo mítico y su condición de utopía materializada gracias a la gran cantidad de comentarios que sobre ella se publicaron en todo el mundo. En España3, por ejemplo, durante los años 1919 y 1920 aparecieron en el catálogo de la editorial Biblioteca Nueva, inmersos en la colección "Las nuevas doctrinas sociales", alrededor de una veintena de libros destinados a explicar lo acontecido en Rusia, entre los que se encontraban varias de las obras escritas por Lenin -El Estado y la revolución proletaria, Ideario bolchevista, El comunismo de izquierda, el capitalismo de Estado y el impuesto en especie y La victoria proletaria y el renegado Kausky-. Además, los sucesos acaecidos en Rusia entre 1917 y 1921 se convirtieron en fuente de inspiración literaria, pues "la Revolución (...) y los revolucionarios como agentes propulsores fueron temas que aparecieron en las novelas desde perspectivas distintas" (Castañar, 1992: 159).

Sin embargo, según ha denunciado Stephen Koch en El fin de la inocencia, la influencia de las ideas de la Revolución en el mundo no sólo se debió a la atracción por los cambios efectuados -analizados en prácticamente todo el mundo como la toma del poder por el pueblo tras siglos de opresión-, sino también y sobre todo a la creación de una complejísima organización de propaganda, dirigida por Willy Münzenberg, encargada de movilizar y controlar a los intelectuales y, gracias a ello, a toda la opinión pública. Koch argumenta en su obra que todo el apoyo que recibió la URSS durante los años treinta por parte de personajes relacionados con la cultura fue minuciosamente planeado y controlado ${ }^{4}$. El escritor y periodista húngaro Arthur Koestler se refirió, hablando de su propia experiencia, a la importancia de la política comunicativa efectuada por los comunistas como factor determinante a la hora de valorar el influjo de los postulados de la Revolución:

zanjar, sin vacilaciones, esta grave cuestión: ¿van a estar con los pueblos que exigen transformación radical de todas las formas de la vida, o con el capital, defendiendo al antiguo régimen?" (c. 1930: 97).

${ }^{3}$ Según Julián Gorkin, "quizá haya sido España el país donde se han editado más libros sobre la Revolución Rusa (...). Los jóvenes españoles, al igual que la parte más adelantada del pueblo obrero, devoraban febrilmente dicha literatura" (Caudet, 1993: 131).

${ }^{4}$ En Alemania, por ejemplo, el poder mediático de los comunistas, ha sido explicado así por el historiador Federico Suárez: "[El Partido Comunista] poseía en Alemania dos diarios de gran circulación, Berlim anm Mergen y Welt am Abend; la revista Arbeiter Illustrieter Zeitung, que aparecía semanalmente con un millón de ejemplares y que constituía la contrapartida comunista de Life, y una serie de publicaciones varias, entre ellas revistas técnicas para fotógrafos, aficionados a la radiotelefonía, etc., todo ello con un tinte comunista disimulado. (...) Financiaba la representación de piezas teatrales comunistas [y] (...) una sociedad distribuidora de películas, a través de la cual introdujo en Occidente el cine soviético de Eisenstein y Pudorkin. (...) De este modo, la Comisión Mundial de Ayuda a las víctimas del Fascismo Alemán pasó a ser, de una sociedad filantrópica, una organización del movimiento de resistencia subterránea en Alemania y a convertirse en una agencia comunista de propaganda para el todo el mundo con grandes medios" (Suárez, 2002: 19).

La influencia de los comunistas en el ámbito editorial y periodístico en España ha sido estudiada por Francisco Caudet, para quien la presencia comunista alcanzó en la década de 1930 "un enorme y decisivo protagonismo" (1993: 131) en diversos sectores de la sociedad española. 
La idea que me hacía de Rusia era la que la propaganda del Soviet había formado en mi espíritu. Me representaba a Rusia como una América superior, empeñada en la empresa más gigantesca de la historia, bullente de actividad y entusiasmo, nada menos que una gran batalla para dignificar al proletariado creando una sociedad más justa y un 'hombre nuevo' libre de las lacras de la sociedad burguesa (Suárez, 2002: 205).

Aunque la falta de imparcialidad y el deliberado partidismo de casi todos los estudios sobre cultura y comunismo dificultan la comprensión de la relación entre ambos fenómenos, parece necesario tener en cuenta las dos explicaciones clásicas sobre la atracción de las ideas soviéticas sobre la esfera del arte y el pensamiento -referidas tanto a la propaganda como a la necesidad de encontrar un asidero ideológico al que aferrarse en un momento de crisis y desorientación ideológica- para entender el desarrollo del movimiento intelectual en la época. En cualquier caso, y teniendo en cuenta que el fervor demostrado por autores de diversa nacionalidad y cultura sintieron por las teorías comunistas parecía obedecer a una sincera atracción, resulta evidente que el aparato propagandístico comunista "organizó la noción de que el principal escenario de la vida moral, el verdadero reino del bien y del mal, era la política" (Koch, 1997: 34). Los logros políticos y sociales de la Revolución Rusa fueron elevados al plano ético, con lo cual el ideario comunista quedó revestido, a ojos de sus seguidores, de una legitimidad moral necesaria para justificar su postura totalitarista de la que carecían el resto de teorías políticas ${ }^{5}$, como señaló André Malraux: "Aunque la URSS también [como la Alemania nazi] restrinja las libertades, lo hace para permitir por fin el establecimiento de una nueva sociedad" (Tood, 2002: 143).

\section{El viaje hacia una nueva realidad}

Debido al impacto de la Revolución y a las ya mencionadas adhesiones que provocó, fueron muchos los intelectuales y artistas que viajaron a la URSS durante los años siguientes a los sucesos de 1917 para poder comprobar in situ cuál era la realidad del país y cómo estaban afectando a la sociedad los cambios impuestos desde el poder bolchevique. Bernard Shaw, H. G. Wells, John Dos Passos, Henri Barbusse, André Gide, André Malraux, Halldor Kiljan Laxness, Stefan Zweig, Max Aub, Rafael Alberti, María Teresa León, Miguel Hernández, Ramón J. Sender, Fernando de los Ríos o Pablo Neruda fueron algunas de las personalidades culturales y políticas de la época que se desplazaron para observar el alcance de la revolución en las décadas de 1920 y 1930, poniendo así de manifiesto que "Rusia se había convertido para todos los intelectuales en el país más fascinante de la posguerra; [pues] allí se estaba gestando algo nuevo" (Zweig, 2002: 413). El foco de atracción que suponía el nuevo país soviético forjado sobre los escombros de la vieja Rusia fue gráficamente puesto de

\footnotetext{
${ }^{5}$ Para entender las adhesiones que provocó la política comunista a pesar de sus componentes totalitarios, se ha de tener en cuenta que, para buena parte del cuerpo intelectual de la época, la elección política no se planteaba entre comunismo y democracia, sino, más bien, entre comunismo y fascismo. Asumir esa bipolaridad, frecuentemente expuesta por autores como André Malraux, resulta de suma importancia para comprender el desarrollo político e ideológico de la época.
} 
manifiesto por André Gidé, quien manifestó que "para presenciar la renovación, bien valía la pena vivir" (1982: 22). En general, y salvo casos excepcionales como el de Max Aub -que acudió enviado por el periódico madrileño Luz para elaborar una serie de artículos sobre la situación del teatro en el país- o el del escritor norteamericano John Dos Passos -que reconoció viajar para poder estudiar las características de las artes escénicas soviéticas y “de paso (...) saber cómo vivía la gente en un régimen socialista" (1984: 212)-, los autores que partieron hacia la URSS lo hicieron cegados por el brillo de la revolución y, por tanto, condicionados por la imagen mítica que les había llegado del acontecimiento.

Muchos de los intelectuales que viajaron a Rusia escribieron, bien de forma inmediata, bien tras el paso del tiempo, sus experiencias y sus impresiones sobre el país soviético. En algunos casos, como el de Alberti -para quien su estancia en la URSS en 1932 fue "como realizar un viaje del fondo de la noche al centro de la luz" (1997: 26)- los testimonios sirvieron para alabar el régimen, relatar al resto del mundo las bondades de los sistemas sociales, productivos y políticos instaurados después del triunfo de la Revolución y convertirse de este modo en los "ingenieros de almas" que demandaba Stalin.

La condición novedosa de lo que estaba ocurriendo en Rusia dota a estos libros de viajes de un tono similar al de las crónicas del Nuevo Mundo en las que los navegantes y los soldados españoles intentaban relatar las características de las nuevas sociedades descubiertas allende los mares. Plantear el fin de las divisiones sociales, la aniquilación del sistema capitalista y la industrialización de una sociedad eminentemente agraria como era la de la antigua Rusia suponía concebir un nuevo modelo tan diferente al convencional como lo pudieron ser los antiguos grupos de población americanos para los colonos españoles. La visión de ese "nuevo mundo" reforzó la filiación comunista de muchos de los escritores que viajaron hasta allí. Rafael Alberti, fascinado por la idea de haber encontrado en los territorios soviéticos un nuevo modelo humano, fruto de una sociedad diferente y ejemplar, expresó su admiración por los efectos que la Revolución había tenido en la ciudadanía:

\footnotetext{
Si hay hombres que puedan considerar la tierra que trabajan, que los nutre de pan y de respiro, como sustancia de su propio ser, son esos rusos que ahora, y al cabo de veinticinco años de paz arrancada a una de las más cruentas guerras, han hecho de su vida un largo insomnio, una incesante pleamar de valor, un ancho espejo donde mirarse y aprender lo bueno que aún le queda al planeta (1999: 111).
}

Pablo Neruda evidenció también este carácter edénico en su libro de memorias Confieso que he vivido al referirse a las sensaciones que le producía el recuerdo de la ciudad de Moscú, visitada por él en múltiples ocasiones: “Moscú (...) es para mí (...) la magnífica capital del socialismo, la sede de tantos sueños realizados. (...) Moscú es para mí una fiesta" (1984: 309).

La postura de estos escritores, similar a la de muchas otras personalidades culturales, políticas y artísticas del siglo XX defensoras de la ideología comunista y de su implantación en la antigua Rusia, ha sido objeto de 
numerosas críticas, lanzadas en muchos casos después de 1989, cuando la caída del comunismo permitió un conocimiento global y exacto de las circunstancias que rodearon a la sociedad soviética. La falta de libertad, la violencia ejercida desde el Estado, las necesidades de la población o la absoluta imposibilidad de disidencia fueron algunas de las taras del régimen comunista que se esgrimieron como objeciones a la postura de absoluto apoyo de estos intelectuales. El escritor inglés Martin Amis, muy crítico con la postura de los pensadores y artistas que apoyaron públicamente a la URSS, afirmó recientemente que "hubo una especie de epidemia de desinterés colectivo, un juego psicológico que comenzó como autohipnosis y prosiguió como histeria colectiva" (2006: 48) que hizo ignorar todos los aspectos negativos del régimen comunista. De forma más benévola, Ella Braguinskaya ha explicado que quienes visitaron la URSS no pudieron ser conscientes de la ineficacia e injusticia del sistema, pues sólo se les mostró una realidad que casi no tenía nada que ver con la realidad verdadera:

Nunca estuvieron en la URSS, sino en un país virtual. Y con la 'ayuda' de sus amigos soviéticos, que durante muchos años también creyeron ciegamente en tan bella utopía, (...) los grandes de nuestro siglo (...) presentaban a Occidente una imagen bella e ilusoria, (...), la imagen de un sueño (6).

\section{Desengaño y crítica}

Junto a esta visión mítica y sublimada, existen en la literatura de viajes a la URSS una serie de textos escritos por autores que experimentaron un profundo desengaño al comprobar de primera mano cómo se estaban realizando las transformaciones sociales, políticas y económicas en la antigua Rusia. En algunos casos, las sensaciones provocadas por el descubrimiento de la nueva sociedad fueron incluidas en libros autobiográficos -como hizo Stefan Zweig, quien dedicó un capítulo de sus memorias El mundo de ayer. Memorias de un europeo a su estancia en Moscú en 1928, en el marco de los actos conmemorativos del centenario del nacimiento de Tolstoi- o en dietarios de viajes que no sólo incluían referencias a la URSS -como en Años inolvidable y Oriente Express, las obras con las que el escritor norteamericano John Dos Passos dio cuenta de sus diversos viajes por Europa y Asia durante las décadas de 1920 y 1930-. En otros, en cambio, la experiencia soviética fue tan intensa y produjo en sus autores una crisis ideológica de dimensiones tan vastas que fue tema central de todo un libro. Es el caso de, por ejemplo, Rusia al desnudo ${ }^{6}$, escrita por el autor rumano Panait Istrati, Mi viaje a la Rusia sovietista, firmada por el político y intelectual español Fernando de los Ríos o Retorno de la URSS, compuesto por André Gide en 1937 y ampliado y modificado poco después por Retoques a mi regreso de la URSS. A pesar de ser la de más tardía redacción y publicación, la obra del francés fue la que más impacto causó en las esferas

\footnotetext{
${ }^{6}$ Compuesta en francés, el título original de la obra Istrati fue Vers l'autre flamme. En inglés fue traducida con el sintomático título de The confession of a loser.
} 
intelectuales, artísticas y políticas de la época7 por el fuerte compromiso comunista de su autor hasta antes de conocer la situación real de la Antigua Rusia $^{8}$.

La denuncia y el descubrimiento al mundo de la verdadera situación de la URSS parecen ser los dos objetivos primordiales de estos textos, en los que es perceptible la aplicación de lo que Alain Finkielkraut ha denominado "imperativo moral de la memoria" (1982: 15). Para el filósofo francés, en determinados momentos de la historia caracterizados por su nivel de tensión y dramatismo, los hombres -especialmente los intelectuales $\mathrm{y}$, en general, todos aquellos poseedores de un lugar de privilegio y liderazgo en la esfera públicaque han sufrido o han sido testigos de la violencia, la intolerancia o la opresión han de ser conscientes de sus deberes éticos y denunciar lo vivido por ellos para poder hacer de su experiencia un testimonio de memoria activa al servicio de las nuevas generaciones (Finkielkraut, 1982: 9-34). En ese sentido, la obra de estos autores ha de ser concebida como una literatura que ayuda a hacer memoria, para poder entender cómo fueron o cómo pudieron ser las víctimas del régimen soviético, negados de voz y condenados al silencio por la interpretación única de la historia propuesta por los poderes comunistas. Es, por tanto, una literatura cargada de valores éticos, pues, como ha señalado María Teresa López de la Vieja “algunas obras literarias pueden 'hacer justicia' (...) al llenar un vacío del conocimiento e incorporar el punto de vista de quienes jamás tuvieron voz en la historia" (2003: 17).

Además de por la intencionalidad de denuncia y por describir el mismo contexto espacio-temporal, estos textos aparecen unidos por adscribirse a diversas variantes del género autobiográfico como son el libro de viajes, la confesión y el testimonio histórico ${ }^{9}$. Mientras que la primera identificación

\footnotetext{
7 Poco después de la publicación de Retorno de la URSS, durante el II Congreso Internacional de Escritores por la Defensa de la Cultura, celebrado en 1937 en Valencia, en plena Guerra Civil Española, José Bergamín -en un discurso publicado meses después en L'Humanité, el periódico del Partido Comunista Francés- tildó a Gide de "enemigo del pueblo español" y a su libro de viajes "propaganda fascista". Ilya Ehrenbourg, por su parte, atacó al autor galo desde las páginas de Izvestia -órgano oficial del Presidio del Soviet Supremo- acusándolo de ser "el nuevo aliado de los marroquíes franquistas, de los camisas negras, el maligno anciano y el plañidero de Moscú". En Pravda, publicación oficial del PCUS que había homenajeado a Gide durante su estancia en la URSS, se le acusó de ser "el típico representante de la burguesía decadente" (Muñoz Suay, 1982: 14 y ss).

${ }^{8}$ En 1935, sólo dos años antes de entrar en contacto directo con la realidad de la URSS, Gide afirmó en el Congreso de Intelectuales Antifascistas celebrado en París que, a pesar de seguir considerándose cristiano, había sido siempre "comunista de corazón y también de espíritu" (1981: 19).

9 La definición de autobiografía propuesta por Philipe Lejeune, ampliamente difundida y asumida por prácticamente toda la comunidad científica, no puede ser asumida por estos textos ni por otros de supuesto carácter autobiográfico, lo que, además de problemas de análisis, ha provocado objeciones y correcciones por parte de sectores de la crítica. $\mathrm{Si}$, como defiende el estudioso francés, una autobiografía es un "relato retrospectivo en prosa que una persona real hace su propia existencia, poniendo énfasis en su vida individual y, en particular, en la historia de su personalidad" (1994: 50), resulta difícil clasificar textos como los libros de viajes -que "no explican la existencia de un individuo ni la historia de su personalidad, sino un segmento de esta personalidad y, en consecuencia, predomina el relato de una experiencia concreta que obstruye la visión reminiscente del propio pasado" (Llorens, 2004: 112), las confesiones -
} 
parece evidente, por cuanto son textos en los que se cuenta el desarrollo de un viaje efectuado por un autor que se identifica tanto con la figura del narrador como con la del personaje -y de ahí su concepción autobiográfica, configurada también por el carácter factual de lo relatado en ellos y por la implícita constitución de "pacto autobiográfico" por la que el sujeto histórico se compromete con los lectores a narrar acontecimientos reales-, las otras dos resultan más problemáticas. Afirmar que libros como los de Gidé o Istrati -o pasajes como los que Zweig o Dos Passos dedican a su experiencia soviéticason confesiones sólo se entiende si se tiene en cuenta que, como señaló María Zambrano, "la confesión es una acción" (1995: 31) que aparece "en momentos de crisis (...) en que el hombre concreto aparece al descubierto en su fracaso" (1995: 39). De hecho, "confesión" es un término que, en su dimensión literaria, remite irrevocablemente al texto en el que San Agustín narró su conversión al cristianismo y del descubrimiento consecuente de una verdad que diera sentido a su vida y le permitiera salir de la situación de crisis y desorientación en que se hallaba. Tanto el concepto de hombre que se ha dado cuenta de su fracaso como el de encuentro de una verdad necesaria ${ }^{10}$ para modificar el rumbo existencial aparecen en los desengañados textos que escribieron quienes, tras conocer in situ la realidad de la URSS, renegaron de la doctrina comunista a la que habían permanecido adheridos. Por último, la adscripción a la categoría de testimonio histórico cobra sentido si se recobra la definición con la que Jean Norton Cru explicó el carácter distintivo de los textos compuestos por autores que mantuvieran el rol de testigos respecto a otros ${ }^{11}$. Para el crítico francés, la

limitadas también a un pasaje concreto del recorrido existencial de un individuo dotado de especial significación- o los testimonios históricos -en los que, más que el propio periplo vital individual, lo que importa es el contexto del que da cuenta el autor, cuya importancia está exclusivamente vinculada a su condición de testigo-, que quedarían, según Mireia Llorens, "flotando en los limbos de la narración no ficcional" (2004: 112). A pesar de la imposibilidad de ser incluidos en la estricta definición propuesta por Lejeune, su carácter factual, la identificación entre las entidades extratextuales e intratextuales vinculadas a las nociones de autor, narrador y personaje y el hecho de dar cuenta de un pasaje vital hacen necesario incluir a estos textos dentro del género autobiográfico. De hecho, los últimos estudios del propio Lejeune, así como los de otros expertos en el ámbito de la autobiografía como Pozuelo Yvancos, abogan por una concesión más flexible de la clásica definición en la que pudiesen encajar todas las variantes autobiográficas (Pozuelo Yvancos: 2006, 15-65).

10 En este caso, el concepto de "verdad necesaria" ha de considerarse equivalente al de "descubrimiento".

${ }^{11}$ Los orígenes de la teoría de Jean Norton Cru pueden rastrearse en un trabajo centrado en las obras testimoniales sobre la guerra que asoló Europa entre 1914 y 1918 -en la que por primera vez en la historia se utilizaron armas de destrucción masiva y la población civil se convirtió en potencial objetivo de las estrategias militares de combate-, en el que el crítico -excombatiente de la I Guerra Mundial, por cierto- señaló que los únicos testimonios válidos sobre la experiencia bélica eran los de los propios combatientes. El hecho de que las versiones oficiales convirtieran la información sobre el conflicto en una continua exaltación patriótica y, sobre todo, mintiesen a la opinión pública, ocultando el verdadero -y elevadísimo- número de muertos y distorsionando el verdadero desarrollo del conflicto provocó que los testimonios de quienes habían participado en la guerra -y, por tanto, habían conocido de primera mano su evolución y características- se convirtieran en una forma de resistencia ante el engaño -prácticamente la única- con el que se quería someter a las sociedades. Cru negó cualquier tipo de validez como testimonio histórico tanto a las obras que no respondían a la verdad de lo sucedido -bien por la 
categoría de sujeto-histórico no sólo hacía referencia al contrato implícito establecido entre autor y lector para narrar acontecimientos reales -o sometidos, al menos, a la percepción que el primero tuvo sobre ellos-, sino también y sobre todo a la dimensión pragmática otorgada por la condición de testigo del autor, causante del análisis diferencial que se reclama para estos textos frente a otros documentos críticos contra el régimen comunista (Cru, 2006).

Los libros de viajes a la URSS fueron concebidos por autores que presentan una misma evolución ideológica. Todos ellos partieron de un mismo sentimiento de admiración, pleno de idealismo, hacia la Revolución Rusa y los cambios efectuados a partir de ella en la sociedad -manifestado, de hecho, en las idílicas descripciones que efectúan de su primer encuentro con el pueblo soviético, llenas de "hombres entrañablemente sencillos" (Zweig, 2002: 416) y de "niños radiantes de felicidad y de salud [que] parecían ofrecer su alegría" (Gide, 1982: 25)- y desembocaron en intensa sensación de desengaño -o de crisis, aplicando la terminología con la que Zambrano estudió los textos confesionales- al comprobar que el régimen soviético no estaba produciendo las transformaciones deseadas y ni siquiera era el modelo político y social ejemplar que se pensaba. Algunos autores, como Gidé o Istrati habían manifestado públicamente su adhesión al ideario comunista y su convencimiento de que la puesta en práctica en la Antigua Rusia era la única vía para luchar contra el capitalismo, mientras que otros, como Zweig o Fernando de los Ríos -político socialista- tan sólo habían mostrado, sin militancia ni compromiso algunos, sus simpatías por el régimen bolchevique. Resulta evidente que la noción de desengaño es mucho más fuerte y traumática en los primeros casos, que aparecen así vinculados a los de otros intelectuales que, como George Orwell o Arthur Koestler, viraron ideológicamente y se mostraron tremendamente críticos con la política estalinista vigente en la URSS durante las décadas de 1930 y $1940^{12}$. El conocimiento real de las condiciones en las que se vivía en la URSS, la falta de libertad absoluta de la sociedad soviética $-\mathrm{y}$, en concreto, de los intelectuales, incapacitados para realizar crítica alguna a los ámbitos

falta o el carácter erróneo de la información, bien por el uso de estereotipos relacionados con la experiencia bélica y su expresión artística- como a aquellas incapaces de transmitir con exactitud las reacciones personales que provoca estar inmerso en un acontecimiento infernal como una guerra.

12 El desencanto político y el rechazo del estalinismo de George Orwell se hizo patente tras su participación como voluntario en la Guerra Civil Española, en la que combatió enrolado en una milicia del POUM y fue testigo de la persecución que dentro del bando republicano llevaron a cabo los comunistas contra las fuerzas revolucionarias: "Desde hace algún tiempo impera un estado de terror: se prohíben partidos políticos, se ejerce un asfixiante censura de prensa, se espía sin cesar y hay encarcelamientos en masa sin juicio previo. Cuando me fui de Barcelona, a fines de junio [de 1937], las cárceles estaban a rebosar (...). Lo que hay que destacar es que los detenidos no son fascistas, sino revolucionarios; no estarán allí por tener opiniones demasiado derechistas, sino por tenerlas demasiado izquierdistas. $\mathrm{Y}$ los responsable de que estén encerrados son esos temibles revolucionarios cuyo solo nombre pone los pelos de punta (...): los comunistas" (2003: 251).

Por su parte, Arthur Koestler -comunista convencido hasta 1940- denunció en su novela El ojo y el infinito el totalitarismo del régimen soviético y los crímenes acaecidos durante los Procesos de Moscú, que, entre 1932 y 1936, supusieron el comienzo de las "purgas estalinistas" que acabaron, en muchos casos por motivos arbitrarios, con cualquier tipo de disidencia. 
gestores de poder-, el tremendo proceso de despersonalización sufrido por el individuo en el contexto del sistema, la corrupción de determinados estamentos del PCUS o la brutal política de represión estalinista son algunos de los temas que aparecen de forma análoga en ambos tipos de textos. ${ }^{13}$

Los autores que viajaron a la Antigua Rusia coinciden en mostrar cómo el objetivo de su obra -“exponer las reflexiones que (...) la URSS ha sugerido", según Gide (1982: 23); "ver claro en el fondo del pensamiento (...) las impresiones y las interrogaciones que una nueva realidad social suscitaba", para Fernando De los Ríos (1970: 10)- resulta difícil de cumplimentar por la ambigüedad y ambivalencia de las sensaciones experimentadas, como expuso el autor de Regreso de la URSS al ser preguntado a su vuelta por los periodistas franceses por sus impresiones del viaje:

La palabra decepción me parece inexacta [para reflejar lo vivido en la URSS], pero no sé que proponer en su lugar (...) Lo bueno y lo malo se reflejan en ese país, debería decir, lo excelente y lo peor (Muñoz Suay, 1982: 16).

Similares dificultades para expresar con exactitud lo sentido al ver las carencias y los problemas de la sociedad soviética experimentó el escritor norteamericano John Dos Passos, cuya postura crítica hacia el comunismo se acrecentó durante la Guerra Civil Española. La relación de los servicios de espionaje soviéticos con la desaparición de su amigo -y traductor de su obra al español- José Robles intensificó la vehemencia de los ataques del estadounidense hacia el régimen soviético que, no obstante, habían comenzado durante su viaje a la URSS en la década de 1920, que dejó en él una extraña sensación al presenciar simultáneamente los avances y los efectos negativos de la Revolución:

¿Era toda aquella hambre y pobreza necesaria para la edificación de la nueva sociedad socialista o el resultado de una opresión centralizada, ignorante y falta de flexibilidad? El camarero con un sucio delantal, que acababa de traerme la cena, ¿era más feliz ahora de lo que hubiera sido bajo los zares? ¿Era mejor camarero, mejor ciudadano, tenía mejores oportunidades de estudiar idiomas -me había dicho que estaba tratando de aprender francés-, de jugar al ajedrez, de hacer el amor con su mujer y de criar limpios y saludables hijos de ojos brillantes? (Dos Passos: 1984: 237)

Reflejar esa dialéctica constituye uno de los tópicos de estas obras. Junto a la crítica del sistema en el que se había creído, existe una valoración positiva de la sociedad soviética, y de algunos de los logros que se consiguieron. Es frecuente,

\footnotetext{
${ }^{13}$ En algunos libros autobiográficos de supervivientes del Gulag, como los de Natalie Ginzburg o Margarete Buber-Neumann se hace también hincapié en las paupérrimas condiciones de vida de la mayor parte del pueblo soviético. Aunque sus obras están centradas en las penurias de la vida en los campos de concentración -y de ese modo se relacionan como "imperativo moral" con los libros de viaje estudiados en este artículo-, incluyen también reflexiones sobre la vida en las ciudades rusas, cuya ausencia de libertad y presencia de instrumentos de control y represión era tal que, como señaló Buber-Neumann, los individuos acostumbraban a sentir la "angustia del que todavía está libre" (2005: 27).
} 
de hecho, señalar la alegría del pueblo ruso, y el entusiasmo con el que acogió los procesos revolucionarios. Stefan Zweig, por ejemplo, habló de la "camaradería sincera (...) y cordialidad espontánea" de los soviéticos, consciente de "haber visto la 'verdad' y (...) llevar a cabo aquello que los otros [pueblos] apenas soñaban" (2002: 423), mientras que Gide se refirió a la "cordialidad repentina, natural y (...) encantadora" (1982: 25) con la que fue recibido. Bajo ambas concepciones de la sociedad -similares a las manifestadas también por intelectuales que continuaron siendo afines al régimen, como la ya citada de Rafael Alberti- parece subyacer el orgulloso comportamiento del pueblo ruso, henchido por formar parte del primer proyecto colectivo de la historia en el que se estaban poniendo en práctica las propuestas teóricas de Marx y Engels y por creerse situado a la cabeza del desarrollo económico e industrial del mundo debido a la falta de información existente entre la población rusa. Así lo evidenció Zweig, sorprendido por la ingenuidad de los ciudadanos soviéticos, que, al ver por primera vez determinados avances técnicos, pensaban que habían sido concebidos por la propia Revolución:

Cuántas veces se nos escapaba una sonrisa cuando nos enseñaban unas fábricas mediocres y esperaban que nos quedáramos maravillados como si nunca hubiéramos visto nada parecido en Europa o en América; 'eléctrica' me dijo maravillado un obrero, señalándome una máquina de coser con la esperanza de que me deshiciera en admiraciones. (...) ‘Que niño más grande, inteligente y bondadoso es esta Rusia', pensaba yo (2002: 420).

Max Aub también fue consciente de la ilusa felicidad de la sociedad, tal y como manifestó en uno de los artículos periodísticos que escribió en el periódico $L u z$ en los que, además de cuestiones teatrales, intentó transmitir "una mirada sincera al Estado de Rusia" (Aznar Soler, 1993: 39):

El ruso hoy es un hombre feliz que cree vivir en el mejor de los mundos. No me negará que tiene su importancia. Está convencido de que los obreros del resto de la humanidad (...), andan bajo el látigo de los capataces, igual que los soldados bajo los de los capitanes (...) Son felices. Desconocen otra cosa (Aznar Soler, 1993: 40).

De este modo se ponía de manifiesto la censura a la que estaba sometida la población soviética, incapaz de saber qué estaba ocurriendo en el exterior y de evaluar correctamente, por tanto, su situación. El control de la información por parte del régimen fue otra de las críticas que forma sistemática aparecieron en los textos testimoniales de los autores que viajaron a la URSS. No sólo se cuestionaba la falta de referencias que los soviéticos tenían del exterior, sino también la prohibición de emitir juicios negativos contra el poder y el minucioso ocultamiento de los problemas de la sociedad que los miembros del partido realizaban para que los viajeros occidentales no se diesen cuenta de la verdadera situación. El silenciamiento de las opiniones disidentes no es exclusivo, evidentemente, de los textos sobre la URSS, sino que aparece en todos los libros destinados a relatar la cotidianeidad de un sistema totalitario. De ahí que Max Aub escribiese en su viaje a la España franquista en 1969 desde el exilio mexicano que el régimen de Franco "había tenido la habilidad de dejar 
en babia a todo el país" (Aub, 2003: 315) o que supervivientes de los campos de exterminio nazis como Elie Wiesel manifestasen que, antes de su internamiento, “nadie había oído jamás el nombre de Auschwitz" (Wiesel, 1986: 43), pues su sola mención hubiera supuesto un acto de crítica contra el poder hitleriano. Es sintomático, de hecho, que André Gide identificase la falta de libertad de expresión de la URSS con la de la Alemania nazi:

La mínima protesta, la mínima crítica, ya expuesta a las penas mayores, se ve (...) inmediatamente ahogada. Y dudo que en ningún otro país hoy por hoy, ni siquiera la Alemania de Hitler, exista espíritu menos libre, más doblegado, más temeroso aterrorizado- , más avasallado (1982: 52).

La creación de una interpretación única para todo, coincidente con la expresada por las altas esferas del PCUS, provocó que, como señaló Gide, "[en la URSS] en todo, y sobre cualquier tema, no puede haber más de una opinión" (1982: 41). Fernando De los Ríos, en el análisis de las instituciones culturales soviéticas que realizó en Mi viaje a la Rusia sovietista, expuso el criterio censor y depurador que regía en las bibliotecas y centros de enseñaza, la propaganda que incluían los libros de texto utilizados en las escuelas y el dogmatismo de los sistemas educativos, culturales y periodísticos rusos, destinados a ofrecer una única interpretación de los acontecimientos susceptible de ser asimilada por la población (1970: 152 y ss). Esa obsesión por mantener una única voz oficial llevaba a la persecución de todo aquel que intentaba protestar contra el sistema. John Dos Passos y Panait Istrati fueron dos de los autores que más críticos se mostraron con este aspecto de la política soviética, relatando sus encuentros con ciudadanos a los que prácticamente todo se les había prohibido, que vivían con una continua sensación de miedo en el primero de los casos y refiriendo situaciones de persecuciones y allanamientos policiales en el segundo.

Por otro lado, la creación de un sistema de vigilancia continua que permitirse controlar las acciones de los viajeros y, de ese modo, simular ante ellos el bienestar del país visitado, es una acción propia de los estados totalitarios y policiales capaces de controlar todo para su propio beneficio. Jorge Edwards lo evidenció en Persona non grata, el libro que compuso tras pasar en su condición de diplomático del gobierno chileno una temporada en Cuba en 1970 -en un contexto geográfico y temporal diferente pero evidentemente relacionado, no obstante, con el soviético por el ordenamiento social y político-, al denunciar cómo fue víctima de espionajes y seguimientos por parte de las autoridades para poder controlar sus movimientos y evitar así que conociese determinados aspectos de la sociedad y la política cubana de la época (2006: 46129).

Durante su viaje a la URSS, Fernando de los Ríos comentó asombrado cómo conoció casi por azar, sin que su encuentro con ella estuviese previsto dentro del programa de su viaje, a la única persona a la que vio pasar penurias económicas durante su estancia en Moscú y, por tanto, la única muestra de desequilibrio social que percibió:

Como preguntase un día a una de las mujeres que allí trabajaban en la limpieza de las habitaciones por qué estaba tan calzada y tan desabrigada, contestóme, 
mediante una persona que conocía el ruso, que no había recibido, en seis meses que hacía abandonó la aldea, ni una prenda de las organizaciones oficiales, y que como le daban 4.000 rublos al mes y no es fácil hallar unas botas fuertes en el mercado clandestino por menos de 100.000, le era imposible pensar en adquirirlas. (...) Los empleados no del hotel, sino de la Internacional, no carecían de nada (1970: 56).

También Stefan Zweig fue consciente del control al que fue sometido durante su viaje y de la imposibilidad que durante el tiempo que permaneció en la URSS tuvo de reunirse de forma aislada con ciudadanos soviéticos:

Sólo cuando cerré la puerta de mi habitación de hotel me quedé realmente solo, solo por primera vez después de doce días, en los que siempre había ido acompañado (...). Metí la mano en un bolsillo. [Encontré] una carta (...) escrita en francés (...) que alguien debía de haber deslizado hábilmente en mi bolsillo (...). Sin firma, (...) rebosaba irritación ante la creciente limitación de la libertad en los últimos años. 'No crea todo lo que dicen -me escribía el desconocido-. No olvide que, a pesar de todas las cosas que le enseñan, dejan de enseñarle otras muchas. No olvide que las personas que hablan con usted, por lo general no le cuentan lo que les gustaría contarle, sino sólo aquello que se les permite decir. Nos vigilan a todos, incluido usted. Su intérprete informa de todo lo que se dice. Su teléfono está interceptado y controlados todos sus pasos'. (...) Quemé la carta, siguiendo las instrucciones de su autor. 'No se limite a romperla, pues recogerían los trozos de su papelera y la reconstruirían'. Y por primera vez me puse a reflexionar sobre todo eso. ¿No era un hecho real que, en medio de tanta cordialidad sincera, de toda aquella espléndida camaradería, no había tenido ni una sola ocasión de hablar con alguien en privado y con libertad? (2002: 425-426).

De forma irónica y muy clarificadora, Max Aub, quien había acudido a la URSS para conocer de primera mano la situación del teatro y presenciar los avances de los autores y escenógrafos rusos, expresó el control de las autoridades sobre las acciones de los viajeros y el intento de presentar ante ellos una imagen sublimada de la sociedad no coincidente con la real para garantizar así su apoyo en las esferas intelectuales y políticas de Occidente. Según Aub, "uno ha ido a Rusia a ver teatro, y ha visto teatro por la mañana, por la tarde, por la noche" (Aznar, 1993: 55).

En ocasiones, el control sobre los viajeros devino en manipulación sobre sus propias acciones, tal y como le ocurrió a André Gide, que hubo de aceptar que sus discursos y declaraciones públicas fueran convenientemente retocados ${ }^{14}$. Incluso, a su paso por Gori, el pueblo natal de Stalin, fue corregido por el jefe de correos local, a quien quería entregar un telegrama dirigido al líder soviético con un poema laudatorio que la visita a su localidad de nacimiento le había provocado. El tratamiento de "usted" con el que Gide se dirigía a Stalin no fue considerado correcto por el funcionario postal, que obligó al autor francés a interpelar al jefe comunista como "jefe de los trabajadores" y "padre de los pueblos" (Gide, 1982: 54-55). Además de evidenciar el culto a la personalidad existente en el régimen, también manifestado en la cantidad de imágenes de Stalin, que, a modo de iconos, poblaban las calles y las casas de todo el país, la

\footnotetext{
${ }^{14}$ Así, del "porvenir de la URSS" se pasa al "porvenir glorioso de la URSS", y de los "grandes espíritus de la monarquía" se pasa sencillamente a los "espíritus de la monarquía".
} 
anécdota pone de manifiesto la absoluta falta de libertad y el control de absolutamente todas las facetas de la vida por parte de las esferas de poder.

\section{Testimonios de un engaño}

Las críticas contra el control de información no sólo iban dirigidas a lo que ocurría en el interior del país, sino que los autores acusaron también al régimen soviético de haber dado al resto del mundo una imagen distorsionada de los efectos de la Revolución. En ese reproche se evidencia el desencanto y la sensación de haber fracasado experimentada por quienes habían creído en la utopía comunista, tal y como señaló André Gide:

Lo que yo reprocho ante todo a la URSS es el habernos dado gato por liebre al presentarnos como envidiable la situación de sus obreros. Y reprocho a nuestros comunistas -no hablo, ¡claro!, de los camaradas engañados, sino de los que sabían $\mathrm{o}$, al menos, hubieran tenido que saber- el haber mentido a los obreros, inconsciente o deliberadamente y en tal caso por consideración política (Gide, 1982: 102).

La impresión de haber sido estafados se convierte así en el elemento central de estos textos, que no pueden, por tanto, ser considerados como meras advertencias efectuadas para reparar en los aspectos más preocupantes del sistema, sino, más bien, como auténticas confesiones surgidas en un momento de verdadera crisis. El carácter cosmogónico del comunismo, que más que una mera ideología política suponía toda una forma de vida, hizo que quienes terminaron por renegar de él sintieran un vacío, una sensación de absurdo similar a la experimentada por quien es engañado y, al mismo tiempo, un descubrimiento de "verdad" esencial que, como el de San Agustín al abrazarse al cristianismo, hizo de su viaje a la URSS un momento clave en su periplo existencial. Así se explica que, por ejemplo, la presencia de pobreza en la sociedad soviética fuese interpretada por estos autores, más que como un puntual problema social, como una muestra del fracaso del proyecto revolucionario que pretendía finiquitar las clases sociales $\mathrm{y}$, sobre todo, del desengaño provocado por el descubrimiento de una realidad que se creía eliminada por el régimen. Como manifestó Gide, "[en el viaje] abrigaba la esperanza de que ya no vería pobres, o para ser más exacto: para dejar de verlos es por lo que fui a la URSS" (1982: 49).

Este carácter traumático es el que dota de interés a unos textos que, por los demás, inciden en algunos de los tópicos con los que comúnmente se ha criticado a lo largo de la historia a los regímenes comunistas y, en concreto, al soviético: falta absoluta de iniciativa individual, totalitarismo, fracaso en el intento de establecer una auténtica homogeneización social, desequilibrio y carencia absoluta de recursos de gran parte de la población, mantenimiento de una elite formada por miembros del partido comunista, fomento de un sentimiento social de miedo y desconfianza, silenciamiento de la crítica y la disidencia, imposición de una voz única, organización de acciones de violencia desde el poder, culto ególatra a la personalidad de los dirigentes políticos y sindicales, permisividad hacia ciertos actos ilegales como el desarrollo del comercio clandestino... 
A pesar de que durante los últimos años, especialmente a partir de la caída del Muro de Berlín en 1989, diversos sectores conservadores y liberales del pensamiento occidental han utilizado los libros de viajes reseñados en este artículo como argumento para denigrar al régimen soviético, llegando en ocasiones a sesgar voluntariamente su sentido y ocultando que la mayoría de quienes mostraron su desengaño por lo ocurrido en la URSS no dejaron de defender que, como dijo André Gide, "no puede bastar con los errores particulares de un país para comprometer la verdad de una causa internacional, universal" (Gide, 1982: 24), se ha de intentar no limitar el alcance de estos textos a sus implicaciones ideológicas y políticas. Como respuestas literarias a un trauma personal y a una situación de injusticia, las obras han de vincularse tanto con el efecto catártico de la literatura como con su potencial condición de "imperativo moral", mientras que las analogías existentes en ellas tienen que relacionarse con la universal sensación de desengaño y crisis que las da origen.

\section{BIBLIOGRAFÍA}

Alberti, R. (1997): La arboleda perdida II. Tercero y cuarto libros (1931-1987), Madrid, Alianza.

Alberti, R. (1999): Imagen primera de..., Barcelona, Seix Barral.

Amis, M. (2006). Koba el temible. La risa y los Veinte millones, Barcelona, Anagrama.

Aub, M. (2003), La gallina ciega. Diario español, Barcelona, Alba.

Aznar Soler, M. (1993), Max Aub y la vanguardia teatral. Escritos sobre teatro 1928-1938, Valencia, Universidad de Valencia.

Braguinskaya, E.: "Rafael Alberti y Rusia en Rafael Alberti o la arboleda más perdida" http://hispanismo.cervantes.es/documentos/Braguinskaya.pdf (Consultado en octubre de 2007).

Buber-Neumann, M. (2005), Prisionera de Stalin y de Hitler, Galaxia-Gutemberg, Barcelona.

Castañar, F. (1992), El compromiso en la novela de la II República, Madrid, Siglo XXI.

Caudet, F. (1993): Las cenizas del Fénix. La cultura española en los años 30, Madrid, Ediciones de la Torre.

Cru, J. N. (2006): Témoins, Nancy, Presses universitaires de Nancy.

De los Ríos, F. (1970): Mi viaje a la Rusia sovietista, Madrid, Alianza.

Dos Passos, J. (1984): Años inolvidables, Barcelona, Seix Barral.

Edwards, J. (2006): Persona non grata, Madrid, Alfagura.

Finkielkraut, A (1982): El judío imaginario, Barcelona, Anagrama.

Garfías, P. (2001): Prosa reunida, Sevilla, Renacimiento.

Gide, A. (1981): Defensa de la cultura, Madrid, Ediciones de la Torre.

Gide, A. (1982): Retorno de la URSS, seguido de Retoques a mi regreso de la URSS, Barcelona, Muchnick.

Gorki, M. (c. 1930): ¡En guardia!, Barcelona, Europa-América.

Koch, S. (1997): El fin de la inocencia, Barcelona, Tusquets.

Lejeune, P. (1994): El pacto autobiográfico y otros estudios, Barcelona, Megazul-Endymion.

López de la Vieja, M. T. (2003): Ética y literatura, Madrid, Tecnos.

Llorens, M. (2004): Autobiografía y ficción épica, Madrid, Biblioteca Nueva.

Muñoz Suay, R. (1982): "Prólogo inicial" en Gide, A. (1982), 11-16.

Neruda, P. (1984). Confieso que he vivido, Barcelona, Seix Barral. 
Orwell, G. (2003): Orwell en España. Homenaje a Cataluña y otros escritos sobre la Guerra Civil Española, Barcelona, Tusquets.

Pozuelo Yvancos, J. M. (2006): De la autobiografía. Teoría y estilos, Barcelona, Crítica.

Suárez, F. (2002): Intelectuales antifascistas, Madrid, Rialp.

Tood, O. (2002): André Malraux. Una vida, Barcelona, Tusquets.

Vázquez Montalbán, M. (1998): La literatura en la construcción de la ciudad democrática, Barcelona, Crítica.

Wiesel, E. (1986): La noche, Barcelona, Muchnick.

Zambrano, M. (1995): La confesión: género literario, Madrid, Siruela.

Zweig, S. (2002): El mundo de ayer. Memorias de un europeo, Barcelona, El Acantilado. 